\title{
Occupational Health Risk and Blood Pressure among Salt Workers of Marakkanam, Villupuram District of Tamil Nadu
}

\author{
Dr. Ajeet Jaiswal \\ Assistant Professor, Department of Anthropology, Pondicherry University, Puducherry, India \\ rpgajeet@gmail.com
}

\begin{abstract}
Tamil Nadu is the second biggest producer of salt in India, next just to Gujarat. The salt in the state is produced from saltpans along the seacoast. Specialists' workers working near salt processing plants might breathe in salt particles skimming noticeable all around, prompting an ascent in plasma sodium, which, thus, might build the pulse or blood pressure and the danger of hypertension.

The goal of the present study is to explore work related wellbeing hazard i.e occupational health risk and circulatory strain or blood pressure of salt workers of Marakkanam, Villupuram locale of Tamil Nadu. This cross-sectional study was attempted to determine the prevalence of blood pressure and the danger of hypertension among workers of 18 years or above. The specialists working in brine pans (water with high concentration of salt) situated far from processing plants were characterized as " brine workers " while the workers or laborers who worked with dry salt in the region of salt processing plants were characterized as " non-brine workers". Blood pressure (BP) was measured amid each clinical examination. An aggregate of 142 brine workers and 176 non-brine workers were interviewed and measured using a predesigned and pretested questionnaire.

The outcome uncovered that prevalence Mean systolic blood pressure of non-brine workers $(122.1 \pm 13.3 \mathrm{~mm}$ $\mathrm{Hg}$ ) was significantly higher than that of brine workers $(118.8 \pm 12.8 \mathrm{~mm} \mathrm{Hg}, p<0.01)$. Mean diastolic blood pressure of non-brine workers $(71.5 \pm 10.4 \mathrm{~mm} \mathrm{Hg})$ was significantly higher than that of brine workers $(69.7 \pm$ $9.4 \mathrm{~mm} \mathrm{Hg}, p=0.02)$. The prevalence of hypertension was essentially higher in non-brine workers (12.2\%) than in brine workers $(7.0 \%, p=0.02)$. 16 laborers were monitored while they utilized face masks and spectacles, for six days. Systolic, and diastolic, blood pressure of these laborers started declining on the third day and kept on declining on the fourth day, however stayed stationary up to the 6th day. The concentration of salt particles in the breathing zone of these laborers was $376 \mathrm{mg} / \mathrm{m} 3$ air. Inhalation of salt particles in non- brine workers may be a word related reason or occupational cause for increased blood pressure
\end{abstract}

Keywords: Occupational Health, Blood pressure, Salt Workers, Occupational Health Risk.

\section{INTRODUCTION}

Salt workers are exposed to word related risks like contact with salt crystals and saline solution, physical anxiety, sunlight and glare because of sunlight reflected by salt crystals stones. Not very many studies have recorded the morbidity among the salt laborers. All through the world, most grown-ups or adult spend quite a bit of their waking hours at work. Work gives various monetary and other advantages. At the same time, people at work face a variety of hazards owing to chemicals, biological agents, physical factors, adverse ergonomic conditions, allergens, a complex network of safety risks, and many and varied psychosocial factors. WHO reports that every year an expected 160 million new instances of work-related illness happen and takes 1.7 million lives, representing $3 \%$ of all deaths (1). There is an abundance of scientific evidence showing a direct relation between salt intake and blood pressure (2).

Several studies were carried out on different animals by (3), large population-based studies $(2,4,5,6$, $7)$, epidemiological studies $(8,9,10)$, meta-analyses of clinical trials $(11,12,13)$, and randomized controlled trials $(14,15)$ have shown that blood pressure is directly related to salt intake. People's occupations also have varying impact on their blood pressure $(16 ; 17,18,19,20)$.

Salt workers involved in the process of manufacturing, processing or milling, and packing of salt are exposed to salt through their surroundings or their environment. Since most salt processing plants in India are not completely enclosed, salt particles float in the air in the vicinity of the workers i.e. all 


\section{Ajeet Jaiswal}

around in the region of the laborers. These workers may therefore breathe in considerable amounts of salt during working hours. These salt particles may be inhaled or breathed in and therefore absorbed in the airway surface epithelium $(16,19,21,22,23)$ or the lungs (24). These same fine particles are also able to translocate from the lungs into the circulatory system (24).

Breathed in salt particles may be carried through a continuous upward mucocilliary current on the airway surface to throat, where they can be swallowed. This is liable to increase the plasma sodium level, which in turn may increase the BP (25) and the risk of hypertension in the exposed workers. However, this issue may be totally preventable. This objective was tested through a cross-sectional and experimental study involving salt workers; the results are presented and discussed below.

\section{METHODS}

A cross-sectional study was conducted among 318 salt workers of Marakkanam, Tamil Nadu. Marakkanam is one of the 22 community development blocks in Villupuram district of Tamil Nadu, around 130 kilometers south of Chennai. The major occupations are agriculture; fishing and salt production with salt pans spread over 2000 acres. Around 2000 salt workers dwell in 10 permanent villages located adjacent to the salt pans.

The aim of the study was explained to the subjects. Their age (in years), sex, detailed occupational history (including exact nature of job and duration of working in salt industry) were recorded on schedules especially designed for occupational health examinations.

After obtaining the informed consent, the anthropo-medical examination was carried out like stature or height, weight and blood pressure. Height was measured in centimeters, using an anthropometric rod, while the subject stood erect on a flat platform. After the subject had rested for five minutes in a supine position, the blood pressure was measured in the right arm using digital blood pressure equipment. Three readings were taken. The initial two readings were to acquaint the subjects with the procedure and the third reading was recorded for analysis.

The workers who were involved in crushing, grinding, milling, packing, and loading salt, and who did not work with brine or saline solution, were defined as non-brine workers (176). These workers worked in the vicinity of salt processing plants. Workers who worked with brine pans for the purpose of crystal reshuffling and raw salt heaping were defined as brine workers (142); their site of work was far away from the salt milling plants. The workers who worked as non-brine workers for some time and also worked as brine workers on some other days were excluded from analysis. Workers who were involved in only administrative and other related activities were also excluded from the analysis.

Hypertension was defined as systolic blood pressure more than $139 \mathrm{mmHg}$ and/or diastolic blood pressure $90 \mathrm{mmHg}$ or above (26). Body mass index was calculated as (Weight in $\mathrm{Kg}$ / (Height in meters $)^{2}$ ). Systolic and diastolic blood pressure was compared in the brine workers and non-brine workers. Student's t-test and Chi square test were used to determine the statistical significance of the differences.

Since mean systolic and diastolic blood pressure, and prevalence of hypertension were found to be significantly higher in non-brine workers as compared to brine workers, an intervention study was carried out to test the hypothesis that exposure of non-brine workers to salt particles floating in environment may contribute to rise in their blood pressure.

For this reason, twenty one non-brine workers, working at or near salt processing plants, who volunteered to take an interest in the study, were enrolled. We clarified the study hypothesis and provided them with face masks and spectacles with plain glasses. The masks were dust monitors made of poly vinyl chloride, containing a disposable filter cartridge of nitrocellulose, these covers or masks could filter $82.8 \%$ dust particles of size $10 \mu \mathrm{m}$ or less (27). The workers were trained and motivated to utilize them appropriately while working, and were observed and followed for six successive days. Amid this period, their resting blood pressure was measured in the supine position, before beginning work in the morning. Only sixteen of them regularly attended the worksite and used the face mask and eyeglasses for all six consecutive days, while others were present on some days, but absent on others.

The dust sampler was put at two sites for six days. The particles of $10 \mu \mathrm{m}$ or more were collected at the base of the cyclone of the sampler and those smaller than $10 \mu \mathrm{m}$ were deposited on the filter paper of the sampler. Volume of total air entering the sampler and weight of particles gathered or collected were used to calculate the average concentration of both types of dust in the environment. 


\section{Results}

Table1. Distribution of Study Subjects According to their Characteristics Features

\begin{tabular}{|c|c|c|c|c|c|c|c|c|}
\hline \multirow{2}{*}{\multicolumn{2}{|c|}{ Characteristics }} & \multicolumn{3}{|c|}{ Brine workers } & \multicolumn{3}{|c|}{ Non- brine workers } & \multirow{2}{*}{$\mathrm{P}$ value } \\
\hline & & $\mathrm{N}$ & $\%$ & Mean \pm SD & $\mathrm{N}$ & $\%$ & Mean \pm SD & \\
\hline \multirow{3}{*}{$\begin{array}{l}\text { Age } \\
(\text { Yrs) }\end{array}$} & Males & 119 & 83.8 & $30.7 \pm 9.8$ & 137 & 84.0 & $28.3 \pm 9.4$ & $<0.01 *$ \\
\hline & Females & 23 & 16.2 & $34.2 \pm 8.9$ & 39 & 16.0 & $35.4 \pm 8.5$ & 0.49 \\
\hline & Both Sexes & \multicolumn{3}{|c|}{$32.4 \pm 8.9$} & \multicolumn{3}{|c|}{$31.4 \pm 9.4$} & $0.01 *$ \\
\hline \multicolumn{2}{|c|}{ Literacy $(\%)$} & \multicolumn{3}{|c|}{34.4} & \multicolumn{3}{|c|}{44.6} & 0.04 \\
\hline \multicolumn{2}{|c|}{ Income (Rs Per annum) } & \multicolumn{3}{|c|}{$18510 \pm 134.8$} & \multicolumn{3}{|c|}{$197660 \pm 146.8$} & 0.05 \\
\hline \multicolumn{2}{|c|}{ Smoking Habit (\%) } & \multicolumn{3}{|c|}{32.7} & \multicolumn{3}{|c|}{34.8} & 0.26 \\
\hline \multicolumn{2}{|c|}{ Alcohol users (\%) } & \multicolumn{3}{|c|}{11.7} & \multicolumn{3}{|c|}{12.7} & 0.16 \\
\hline \multicolumn{2}{|c|}{$\operatorname{BMI}\left(\mathrm{Kg} / \mathrm{m}^{2}\right)$} & \multicolumn{3}{|c|}{$18.8 \pm 1.4$} & \multicolumn{3}{|c|}{$18.6 \pm 3.6$} & 0.29 \\
\hline \multirow{2}{*}{$\begin{array}{l}\text { Dietary } \\
\text { Habit }(\%)\end{array}$} & Veg. & \multicolumn{3}{|c|}{32.3} & \multicolumn{3}{|c|}{37.7} & 0.14 \\
\hline & Non Veg. & \multicolumn{3}{|c|}{67.7} & \multicolumn{3}{|c|}{62.3} & 0.14 \\
\hline \multicolumn{2}{|c|}{ Duration of Work (Yrs) } & \multicolumn{3}{|c|}{$12.5 \pm 8.1$} & \multicolumn{3}{|c|}{$9.8 \pm 5.8$} & $<0.01 *$ \\
\hline
\end{tabular}

Above table explain the distribution of Brine workers and Non- brine workers according to their Characteristics features like Age, Sex, Literacy, Income (Rs Per annum), Smoking Habit, percentage of Alcohol users, BMI, Dietary Habit and Duration of Work. Nearly 83-84\% of workers studied were male, working in both the sectors and only $16 \%$ of them are female. Their mean age was about 34-35 years (female) and 28-30 years (male). Nearly 55\% workers were non-brine workers and nearly $44 \%$ were brine workers.

The literacy of non-brine workers (44.4) was higher than brine workers (34.4), similarly the per annum income of non-brine workers was also more than the brine workers. Similar kinds of result was also found in the case of smoking habit, and percentage of alcohol users, as $32.7 \%$ and $11.7 \%$ workers were brine workers and $34.8 \%$ and $12.7 \%$ were non-brine workers. However the BMI of both the groups was almost same and most of the workers of the both the sectors were non vegetarian, only $32.3 \%$ in case of brine workers and $37.7 \%$ in case of non-brine workers were vegetarian. Eventhough the duration of exposure of salt was more in case of brine workers than non brine workers

hardly much significant differences was observed between brine workers and non- brine workers in the case of smoking habit, percentage of alcohol users, literacy, income (Rs Per annum), dietary habit and body mass index.

Table2. Distribution of Brine Workers and Non-Brine Workers According to Systolic and Diastolic Blood Pressure

\begin{tabular}{|c|c|c|c|c|c|c|}
\hline \multirow{2}{*}{\multicolumn{2}{|c|}{ Blood pressure }} & \multicolumn{2}{|c|}{ Brine workers } & \multicolumn{2}{|c|}{ Non- brine workers } & \multirow{2}{*}{$P$ value } \\
\hline & & $\mathrm{N}$ & Mean \pm SD & $\mathrm{N}$ & Mean \pm SD & \\
\hline \multirow{3}{*}{ Systolic BP (Average) } & Males & 119 & $118.8 \pm 10.6$ & 147 & $121.7 \pm 11.5$ & $<0.01 *$ \\
\hline & Females & 23 & $112.3 \pm 15.7$ & 29 & $117.4 \pm 15.4$ & 0.01 \\
\hline & Both Sexes & 142 & $117.7 \pm 11.9$ & 176 & $121.2 \pm 12.4$ & $<0.01 *$ \\
\hline \multirow{3}{*}{$\begin{array}{l}\text { Diastolic BP } \\
\text { (Average) }\end{array}$} & Males & 119 & $68.5 \pm 8.5$ & 147 & $71.7 \pm 11.3$ & 0.09 \\
\hline & Females & 23 & $70.2 \pm 6.7$ & 29 & $74.3 \pm 9.4$ & $0.02 *$ \\
\hline & Both Sexes & 142 & $68.6 \pm 8.5$ & 176 & $70.6 \pm 9.5$ & $0.01 *$ \\
\hline
\end{tabular}

Table 2 reflects the distribution of brine workers and non-brine workers according to Systolic and Diastolic Blood Pressure. Mean systolic blood pressure of male (118.8 \pm 10.6$)$ and female $(112.3 \pm 15.7)$ brine workers were lower than the non-brine workers. However it was higher in the case male workers $(118.8 \pm 10.6,121.7 \pm 11.5)$ of both the groups than female $(112.3 \pm 15.7,117.4 \pm 15.4)$ workers of both the groups. Similarly the Mean diastolic blood pressure of male $(68.5 \pm 8.5)$ and female (70.2 \pm 6.7$)$ brine workers were lower than the non-brine workers $(71.7 \pm 11.3$ (male), $74.3 \pm 9.4$ (female)). However it was higher in the case female workers $(70.2 \pm 6.7,74.3 \pm 9.4)$ of both the groups than male $(68.5 \pm 8.5$, $71.7 \pm 11.3$ ) workers of both the groups. Statistical calculation like two-tailed Student's t-test and Z-test explains a significant difference in both the sexes in the case of Mean systolic blood pressure. 
Table3. Prevalence of Hypertension in Brine Workers and Non-Brine Workers According to Various Characteristics

\begin{tabular}{|c|c|c|c|c|c|c|c|}
\hline \multirow{3}{*}{\multicolumn{2}{|c|}{ Characteristics }} & \multicolumn{3}{|c|}{ Brine Workers } & \multicolumn{3}{|c|}{ Non-Brine Workers } \\
\hline & & \multirow{2}{*}{$\mathrm{N}$} & \multicolumn{2}{|c|}{ Hypertensive Cases } & \multirow{2}{*}{$\mathrm{N}$} & \multicolumn{2}{|c|}{ Hypertensive Cases } \\
\hline & & & No. & $\%$ & & No. & $\%$ \\
\hline \multirow[t]{2}{*}{ Age (Yrs) } & $<40$ & 104 & 6 & 5.7 & 136 & 12 & 8.8 \\
\hline & $>40$ & 38 & 4 & 10.5 & 30 & 7 & 23.3 \\
\hline \multirow[t]{2}{*}{ Gender } & Male & 119 & 9 & 7.5 & 147 & 17 & 11.5 \\
\hline & Female & 23 & 1 & 4.3 & 29 & 4 & 13.8 \\
\hline \multirow[t]{2}{*}{ Literacy } & Illiterate & 92 & 8 & 8.7 & 99 & 14 & 14.1 \\
\hline & Literate & 50 & 2 & 4.0 & 77 & 7 & 9.1 \\
\hline \multirow{2}{*}{$\begin{array}{l}\text { Annual income } \\
\text { (Rs.) }\end{array}$} & $<18000$ & 90 & 5 & 5.6 & 95 & 12 & 12.6 \\
\hline & $>18000$ & 52 & 5 & 9.6 & 81 & 9 & 11.1 \\
\hline \multirow[t]{2}{*}{ BMI $\left(\mathrm{Kg} / \mathrm{m}^{2}\right)$} & $<18$ & 55 & 2 & 3.6 & 68 & 6 & 8.8 \\
\hline & $18+$ & 87 & 8 & 9.1 & 108 & 15 & 13.8 \\
\hline \multirow{2}{*}{$\begin{array}{l}\text { Duration of } \\
\text { Work (Yrs) }\end{array}$} & $<10$ & 58 & 2 & 3.4 & 113 & 11 & 9.7 \\
\hline & $10+$ & 84 & 7 & 8.3 & 63 & 10 & 15.8 \\
\hline \multirow{2}{*}{$\begin{array}{l}\text { Smokers or ex } \\
\text { smokers }\end{array}$} & Smokers & 95 & 7 & 7.3 & 117 & 16 & 13.6 \\
\hline & Non smokers & 47 & 2 & 4.2 & 59 & 5 & 8.5 \\
\hline \multirow{2}{*}{$\begin{array}{l}\text { Alcohol users } \\
\text { OR ex user }\end{array}$} & Yes & 129 & 8 & 6.2 & 159 & 20 & 12.6 \\
\hline & No & 13 & 1 & 7.6 & 17 & 1 & 5.8 \\
\hline \multirow{2}{*}{$\begin{array}{l}\text { Tobacco } \\
\text { Chewing }\end{array}$} & Yes & 108 & 7 & 6.4 & 120 & 15 & 12.5 \\
\hline & No & 34 & 3 & 8.8 & 56 & 7 & 12.5 \\
\hline \multirow[t]{2}{*}{ Diet Pattern } & Vegetarian & 89 & 7 & 7.8 & 118 & 15 & 12.7 \\
\hline & Mixed & 55 & 2 & 3.6 & 58 & 6 & 10.3 \\
\hline \multicolumn{2}{|c|}{ Total Prevalence } & 142 & 10 & 7.0 & 176 & 21 & 11.9 \\
\hline
\end{tabular}

The above table highlights the prevalence of hypertension in brine workers and non-brine workers according to various characteristics like Age, sex, literacy, annual income, duration of work or exposure, smoking status, Alcohol users, Tobacco users, Diet Pattern and total prevalence.

Most of the hypertension cases in the case of brine workers were male (7.5\%), more than 40 years of age (10.5\%), illiterate $(8.7 \%)$, having a income of more than 18000 per annum (9.6\%), BMI was more than $18(9.1 \%)$, more than 10 years of exposure $(8.3 \%)$, smokers $(7.3 \%)$ but non alcoholic and not chewing tobacco and are vegetarian in their diet pattern.

Similarly Maximum hypertension cases in the case of non-brine workers were found in case of female $(13.8 \%)$, more than 40 years of age (23.3\%), illiterate (14.1\%), having a income of less than 18000 per annum (12.6\%), BMI was more than $18(13.8 \%)$, more than 10 years of exposure $(15.8 \%)$, smokers (13.6\%), alcoholic (12.6\%), chewing tobacco (12.5\%) and are vegetarian in their diet pattern.

However various characteristics like Age, sex, literacy, annual income, duration of work or exposure, smoking status, Alcohol users, Tobacco users, Diet Pattern shows that the prevalence of hypertension was higher in case of non-brine workers than brine workers, even the total prevalence of hypertension was also higher in case of non-brine workers (11.9) than brine workers (7.0).

\section{Results of Experimental Intervention}

Table4. Mean Working Hours, Period of Use of Protective Devices and Morning Blood Pressure of Workers on the Days of Intervention $(N=16)$

\begin{tabular}{|l|l|l|l|l|l|}
\hline $\begin{array}{l}\text { Day of } \\
\text { intervention }\end{array}$ & $\begin{array}{l}\text { Mean no. of } \\
\text { hours Worked }\end{array}$ & $\begin{array}{l}\text { Mean no. of } \\
\text { hours masks } \\
\text { used }\end{array}$ & $\begin{array}{l}\text { Mean no. of } \\
\text { hours glasses } \\
\text { used }\end{array}$ & $\begin{array}{l}\text { Mean Systolic } \\
\text { Blood Pressure } \\
(\mathrm{mm} \mathrm{Hg})\end{array}$ & $\begin{array}{l}\text { Mean Diastolic } \\
\text { Blood Pressure } \\
(\mathrm{mm} \mathrm{Hg})\end{array}$ \\
\hline $\mathrm{I}^{\text {st }}$ Day & $6.3 \pm 0.6$ & $3.8 \pm 1.1$ & $4.7 \pm 0.7$ & $128.9 \pm 11.2$ & $81.8 \pm 8.9$ \\
\hline II $^{\text {nd }}$ Day & $10.1 \pm 1.5$ & $5.4 \pm 1.4$ & $6.4 \pm 1.5$ & $128.8 \pm 11.9$ & $81.7 \pm 11.8$ \\
\hline III $^{\text {td }}$ Day & $9.8 \pm 1.7$ & $4.5 \pm 1.2$ & $5.1 \pm 1.8$ & $124.5 \pm 10.4$ & $77.5 \pm 8.7$ \\
\hline IV $^{\text {th }}$ Day & $7.8 \pm 0.6$ & $4.3 \pm 1.8$ & $4.7 \pm 1.2$ & $118.6 \pm 9.8$ & $63.7 \pm 7.9$ \\
\hline $\mathrm{V}^{\text {th }}$ Day & $9.4 \pm 0.8$ & $4.1 \pm 1.0$ & $4.4 \pm 0.8$ & $114.9 \pm 7.1$ & $64.9 \pm 8.1$ \\
\hline VI $^{\text {th }}$ Day & $9.2 \pm 1.4$ & $4.7 \pm 1.3$ & $5.1 \pm 1.4$ & $115.7 \pm 6.4$ & $64.0 \pm 5.6$ \\
\hline Total & $8.6 \pm 1.8$ & $4.7 \pm 1.4$ & $5.0 \pm 1.6$ & & \\
\hline
\end{tabular}




\section{Ajeet Jaiswal}

The above table shows the result of experimental intervention, in this experimental intervention, data were filtered based on mean number of working hours, mean number of hours of masks used, mean number of hours glasses used along with mean systolic and diastolic blood pressure of workers according to days of intervention from one to six.

Maximum mean number of working hours was found on IInd Day followed by IIIrd, Vth day and VIth day and minimum mean number of working hours was found on Ist day. However in case of mean number of hours of masks used, Maximum was also found on IInd day followed by VIth and IIIrd day and minimum was found on Ist day. A similar response was also observed in the case of mean number of hours glasses used, as the maximum was found on IInd day. But when we discuss about the mean systolic and diastolic blood pressure of workers, maximum mean systolic and diastolic blood pressure was found on Ist day $(128.9 \pm 11.2$ and $81.8 \pm 8.9)$ followed by IInd $(128.8 \pm 11.9$ and $81.7 \pm 11.8)$ and minimum mean systolic blood pressure was found on $(114.9 \pm 7.1)$ Vth day and diastolic blood pressure was found on $(63.7 \pm 7.9)$ IVth day. So the maen values of both systolic and diastolic blood pressures were decreasing on the IIIrd Day and continue to fall even on IVth day. But remained stationary after that each day.

Table5. Comparison of Mean Systolic and Diastolic Blood Pressures of the Workers on Consecutive Days of Intervention

\begin{tabular}{|c|c|c|c|c|}
\hline $\begin{array}{c}\text { Day of } \\
\text { intervention }\end{array}$ & $\begin{array}{l}\text { Mean Systolic Blood Pressure } \\
(\mathrm{mm} \mathrm{Hg})\end{array}$ & $\mathrm{p}$ value & $\begin{array}{c}\text { Mean Diastolic Blood Pressure } \\
(\mathrm{mm} \mathrm{Hg})\end{array}$ & $\mathrm{p}$ value \\
\hline $\mathrm{I}^{\mathrm{st}}$ Day & $128.9 \pm 11.0$ & \multirow[b]{2}{*}{0.98} & $81.8 \pm 8.7$ & \multirow{2}{*}{0.95} \\
\hline $\mathrm{II}^{\mathrm{nd}}$ Day & $128.8 \pm 11.9$ & & $81.7 \pm 12.7$ & \\
\hline $\mathrm{II}^{\mathrm{nd}}$ Day & $128.8 \pm 11.9$ & \multirow{2}{*}{$0.04 *$} & $81.7 \pm 12.7$ & \multirow{2}{*}{0.16} \\
\hline $\mathrm{III}^{\text {rd }}$ Day & $124.5 \pm 10.2$ & & $77.5 \pm 8.7$ & \\
\hline $\mathrm{III}^{\text {rd }}$ Day & $124.5 \pm 10.2$ & \multirow{2}{*}{$0.03 *$} & $77.5 \pm 8.7$ & \multirow{2}{*}{$0.001 *$} \\
\hline $\mathrm{IV}^{\text {th }}$ Day & $118.6 \pm 9.8$ & & $63.7 \pm 7.7$ & \\
\hline $\mathrm{IV}^{\text {th }}$ Day & $118.6 \pm 9.8$ & \multirow{2}{*}{0.08} & $63.7 \pm 7.7$ & \multirow{2}{*}{0.55} \\
\hline $\mathrm{V}^{\text {th }}$ Day & $114.9 \pm 7.0$ & & $64.9 \pm 8.1$ & \\
\hline $\mathrm{V}^{\text {th }}$ Day & $114.9 \pm 7.0$ & \multirow{2}{*}{0.68} & $64.9 \pm 8.1$ & \multirow{2}{*}{0.65} \\
\hline $\mathrm{VI}^{\mathrm{th}}$ Day & $115.7 \pm 6.4$ & & $64.1 \pm 5.6$ & \\
\hline
\end{tabular}

The above table explains the comparison of mean systolic and diastolic blood pressures of the workers on consecutive days of intervention. Statistically significant difference was observed in the case of mean systolic blood pressure between IInd and IIIrd day $(0.04 *)$, between IIIrd and IVth day $(0.03 *)$ but was not found in between Ist and IInd day (0.98) intervention, between IVth and Vth day (0.08) and also between Vth and VIth day (0.68) intervention. However in the case of mean diastolic blood pressure between IIIrd and IVth day, $\left(0.001^{*}\right)$ but was not found in between Ist and IInd day (0.95) intervention, between IInd and IIIrd day (0.16) between IVth and Vth day (0.55) and also between Vth and VIth day (0.65) intervention.

\section{DiSCUSSION}

There is an abundance of scientific evidence showing a direct relation between salt intake and blood pressure. Salt workers involved in the process of manufacturing, processing or milling, and packing of salt are exposed to salt through their surroundings or their environment. Since most salt processing plants in India are not completely enclosed, salt particles float in the air in the vicinity of the workers i.e. all around in the region of the laborers. These workers may therefore breathe in considerable amounts of salt during working hours. Breathed in salt particles may be carried through a continuous upward mucocilliary current on the airway surface to throat, where they can be swallowed. This is liable to increase the plasma sodium level, which in turn may increase the BP (25). Keeping in mind the objective of the study, a cross-sectional study was conducted among 318 salt workers of Marakkanam, Tamil Nadu. both systolic and diastolic blood pressure and prevalence of hypertension were recorded to be more in non-brine salt workers who were exposed to a chemical called sodium chloride particles, which is present in the air of the breathing area (27).

After inhaling the salt may be absorbed from respiratory tract $(16,18,19,21,22)$ or may be the mucocilliary current may transmit the salt to pharynx, where it may be swallowed and then absorbed from the digestive tract. This may result in increase in plasma sodium and may be responsible for high blood pressure $(21,22)$. 


\section{Ajeet Jaiswal}

as we all know urinary sodium (indicator of sodium intake ) and plasma sodium are related with blood pressure differences, which are of high importance for the clinical and health expert (28). Eventhough the main or exact reason or mechanism between increased plama sodium and increased blood pressure are not very clear but present knowledge and concept, explains the idea for an increase in extracellular fluid volume but high plasma sodium increases a transfer of fluid from the intracellular to the extracellular space, and stimulates the thirst center

In this way plasma sodium is responsible for an increase in extracellular fluid volume. Eventhough the change in Extra Cellular liquid Volume might have a weight impact, the increase in plasma sodium itself may be responsible for increasing the blood pressure $(21,22)$.

Blood pressure (Systolic and diastolic) and the predominance of hypertension among non-brine (uncovered) workers were contrasted and brine workers, who were not exposed to salt particles in air. BP is influenced by various components, like Age, Sex, Literacy, Income (Rs Per annum), Smoking Habit, percentage of Alcohol users, BMI, Dietary Habit and Duration of Work. Both groups of studied workers did not differ on these parameters.

Nonetheless, Mean systolic blood pressure of male and female brine workers were lower than the non-brine workers. However it was higher in the case male workers of both the groups than female workers of both the groups. Similarly the Mean diastolic blood pressures of male and female brine workers were lower than the non-brine workers (male), (female)). However it was higher in the case female workers of both the groups than male workers of both the groups. Statistical calculation like two-tailed Student's t-test and Z-test explains a significant difference in both the sexes in the case of Mean systolic blood pressure,

However, various characteristics like Age, sex, literacy, annual income, duration of work or exposure, smoking status, Alcohol users, Tobacco users, Diet Pattern shows that the prevalence of hypertension was higher in case of non-brine workers than brine workers, even the total prevalence of hypertension was also higher in case of non-brine workers than brine workers and this consistency further strengthens the above observation. It can, therefore, safely be concluded that blood pressure and prevalence of hypertension of non-brine workers were higher than brine workers. To give new dimension to the study, an experimental intervention was performed; the decline in blood pressure while using face masks and glasses during work time again strengthens this objective. The exact mechanism by which the decline of salt intake could significantly reduce the blood pressure is not clear; similarly the clear cut role of eye glass using it as protective measure and its role in lowering the blood pressure is also not clear. Thus, the results of this intervention study do not fully support the objective that the cause of higher blood pressure and higher prevalence of hypertension in non-brine workers is inhalation of salt particles from the environment. Further studies on salt workers are needed to elucidate our findings.

\section{ACKNOWLEDGEMENT}

A creator is appreciative to present subject and their families for their participation. I am particularly appreciative for the help and support of Prof. A.K. Kapoor and Prof. Satwanti Kapoor and the medical professional of PIMS for their assistance amid exploration during the research.

\section{REFERENCES}

[1] World Health Organization. 2015, Number of work-related accidents and illnesses continues to increase. Joint news release WHO/International Labour Organization.

[2] Stamler J: The Intersalt Study: background, methods, findings. Am J Clin Nutr 1997, 65(Suppl 2):626-642.

[3] Denton D, Weisinger R, Mundy NI, Wickings EJ, Dixson A, Moisson P, et al.: The effect of increased salt intake on blood pressure of chimpanzees. Nat Med 1995, 1:1009-1016

[4] Law MR, Frost CD, Wald NJ: By how much does dietary salt reduction lower blood pressure? I. Analysis of observational data among populations. BMJ 1991, 302:811-815.

[5] Elliott P: Observational studies of salt and blood pressure. Hypertension 1991, 17:13-18.

[6] William MV, Frank MS, Jamy A, Lawrence JA, George AB, Denise G, et al.: Effects of Diet and Sodium Intake on Blood Pressure: Subgroup Analysis of the DASH-Sodium Trial. Ann Intern Med 2001, 135:1019-1028. 
[7] Obarzanek E, Proschan MA, Vollmer WM, Moore TJ, Sacks FM, Appel LJ, et al.: Individual blood pressure responses to changes in salt intake: results from the DASH-Sodium trial. Hypertension 2003, 42:459-67.

[8] Intersalt Cooperative Research Group: Intersalt: an international study of electrolyte excretion and blood pressure: results for 24 hour urinary sodium and potassium excretion. BMJ 1988, 297:319-328.

[9] He J, Tell GS, Tang YC, Mo PS, He GQ: Relation of electrolytes to blood pressure in men. Hypertension 1991, 17:378-385.

[10] Frost CD, Law MR, Wald NJ: By how much does dietary salt reduction lower blood pressure? II. Analysis of observational data within populations. BMJ 1991, 302:815-819.

[11] Midgley JP, Matthew AG, Greenwood CM, Logan AG: Effect of reduced dietary sodium on blood pressure: a meta-analysis of randomized controlled trials. JAMA 1996, 275:1590-1597.

[12] Cutler JA, Follmann D, Allender PS: Randomized trials of sodium reduction: an overview. Am J Clin Nutr 1997, 65(Suppl 2):643-651.

[13] Graudal NA, Galloe AM, Garred P: Effects of sodium restriction on blood pressure, renin, aldosterone, catecholamines, cholesterols, and triglyceride: a meta-analysis. JAMA 1998, 279:1383-1389.

[14] MacGregor GA, Sagnella GA, Markandu ND, Singer DRJ, Cappuccio FP: Double-blind study of three sodium intakes and long-term effects of sodium restriction in essential hypertension. Lancet 1989, 2:1244-1247.

[15] The Trials of Hypertension Prevention Collaborative Research Group: Effects of weight loss and sodium reduction intervention on blood pressure and hypertension incidence in overweight people with highnormal blood pressure: the Trials of Hypertension Prevention, Phase II. Arch Intern Med 1997, 157:657-667.

[16] Waskiewicz J, Zaborski L: State of circulatory system in equipment operators working in harbour. Bull Inst Marit Trop Med Gdynia 1998, 49:87-96.

[17] Anand MP: Prevalence of hypertension amongst Mumbai executives. J Assoc Physicians India 2000, 48:1200-1201.

[18] Hazarika NC, Biswas D, Narain K, Kalita HC, Mahanta J: Hypertension and its risk factors in tea garden workers of Assam. Natl Med J India 2002, 15:63-68.

[19] Tiwai RR, Pathak MC, Zodpey SP, Babar VY: Hypertension among cotton textile workers. Indian J Public Health 2003, 47:34-36.

[20] Chiplonkar SA, Agte VV, Tarwadi KV, Paknikar KM, Diwate UP: Micronutrient deficiencies as predisposing factors for hypertension in lacto-vegetarian Indian adults. J Am Coll Nutr 2004, 23:239-247.

[21] Kilburn KH: A hypothesis for pulmonary clearance and its implications. Am Rev Respir Dis 1968, 98:449-463.

[22] Knowles M, Murray G, Shallal J, Askin F, Ranga V, Gatzy J, et al.: Bioelectric properties and ion flow across excised human bronchi. J Appl Physiol 1984, 56:868-877.

[23] Hazarika NC, Biswas D, Narain K, Kalita HC, Mahanta J: Hypertension and its risk factors in tea garden workers of Assam. Natl Med J India 2002, 15:63-68.

[24] Boucher RC: Human airway ion transport (Part 1 and Part 2). Am J Respir Crit Care Med 1994, 150:271-281 and 581-593.

[25] Knowles MR, Boucher RC: Mucus clearance as a primary innate defense mechanism for mammalian airways. J Clin Invest 2002, 109:571-577.

[26] Jaiswal A: Anthropo-Medical Profile of Textile workers. Alfa publicaltions, Delhi 2012, 66-71.

[27] Aswania O, Chrystyn H: Relative lung and systemic bioavailability of sodium cromoglycate inhaled products using urinary drug excretion post inhalation. Biopharm Drug Dispos 2002, 23:159-163.

[28] Nemmar A, Hoylaerts MF, Hoet PH, Nemery B: Possible mechanisms of the cardiovascular effects of inhaled particles: systemic translocation and prothrombotic effects. Toxicol Lett 2004, 149:243-253. 


\section{AUTHOR'S BIOGRAPHY}

Dr. Ajeet Jaiswal, is an Assistant professor at Department of Anthropology, Pondicherry University, Puducherry, India $\mathrm{He}$ is a renowned author of six books, more than 50 research papers and articles in International and National reputed, referred and peer reviewed research journals, books and Magazines. He has prepared the Financial and Physical performance annual progress report (200809), Ministry of Rural Development, Govt. of India. He has attended many International and National Seminars, Workshops, Lectures, Exhibition, Orientation Courses, Refresher Courses and Summer Courses. He is also a member of several International and National Anthropological and Public health organization and has also taken part in various Anthropological Development Programmes. 